\title{
KNOWING AND NOT KNOWING ABOUT TRAUMA: IMPLICATIONS FOR THERAPY
}

\author{
RACHEL E. GOLDSMITH, M. ROSE BARLOW, AND JENNIFER J. FREYD \\ University of Oregon
}

Levels of awareness for trauma and their consequences for research, treatment, and prevention within professional psychology and society are considered. When people must endure chronically traumatic environments, it may be adaptive to isolate from awareness information that would produce cognitive dissonance and threaten necessary relationships. Unawareness may also facilitate functioning in environments that invalidate the prevalence and impact of trauma. In addition, characteristics of the posttraumatic environment can promote or impede individuals' awareness of trauma and their psychological functioning. Though often initially adaptive, unawareness for trauma is linked to intergenerational transmission of trauma and its effects and may preclude public and professional attention to trauma treatment and prevention. Understanding the processes through which individuals become unaware or aware of traumatic experience is therefore essential to conducting

Rachel E. Goldsmith, M. Rose Barlow, and Jennifer J. Freyd, Department of Psychology, University of Oregon.

Correspondence concerning this article should be addressed to Jennifer J. Freyd, PhD, Department of Psychology, 1227 University of Oregon, Eugene, OR 97403-1227. E-mail: jjf@dynamic.uoregon.edu effective psychotherapy with trauma survivors.

As a European American, Jewish elementary school student in the ethnically diverse Oakland, California, public school system in the 1980s, I (Rachel E. Goldsmith) was aware of our school's overt emphasis on affirming diverse cultures. I also recall tension between ethnocultural groups, though at the time I do not believe my thinking incorporated awareness for my discomfort or for the dynamics of inequality at my school. I remember one instance of participating in a disruptive argument with an African American girl, for which we were both sent to the principal's office. Before hearing our stories, the principal said immediately, "Rachel, you can go," and she detained the other girl. Although I remember feeling vindicated, 15 years later I reinterpreted my memory as racism. At the time I was neither aware that my principal's response was racist or oppressive, nor would it have been acceptable for me to challenge her decision.

I never "forgot" the incident, yet I do not recall consciously reflecting on or discussing it until the last year or two. Reinterpreting this memory activated other memories of subtle discrimination by teachers. I realized that, in general, the European American children in my elementary school were treated as if we were likely to succeed academically and eventually attend college, whereas the African American children were not. If someone had asked me when I was 10, "Have your teachers or principals displayed racist behavior?" I would have replied that they had not; however, today I would say they had. What motivated the reappraisal of my experiences? Was it the expansion of my understanding of racism to include forms more subtle than slavery and segregation? Did I have an emotional need to believe that my teachers and principal were fair? How did my 
unawareness facilitate my own racist reaction? Might my perception have been different had someone asked me whether racism existed in my school or if I had discussed the experience with someone else at the time? How have the conversations about this incident I have had over the last year shaped my present memory and interpretation?

Traumatic stress can be conceptualized as a combination of the impact of the stressor and the capacity for posttraumatic environments to provide care and support for healing (deVries, 1996). For individuals who experience chronic trauma and whose posttraumatic social environments may act to discourage awareness of trauma, recovery from the adverse impact of trauma may not be adaptive and thus may be rendered difficult or even impossible. Empirical study demonstrates a range of cognitive and relational adaptations to chronic trauma that often endure until environments facilitate recovery. These alterations in functioning include dissociation (e.g., Bernstein \& Putnam, 1986; Chu \& Dill, 1990; Macfie, Cicchetti, \& Toth, 2001; Putnam, 1996), alexithymia (e.g., Berenbaum, 1996; Goldsmith \& Freyd, in press; van der Kolk \& McFarlane, 1996; Zlotnik, Mattia, \& Zimmerman, 2001), memory impairment (e.g., Sargant \& Slater, 1941; Sheflin \& Brown, 1996), relational disturbances (e.g., Berenbaum, 1996; Bowlby, 1988; Linehan, 1993), and neurophysiological changes (e.g., Glaser, 2000; Nelson \& Carver, 1998; Teicher, 2002).

Elements of denial regarding trauma and its effects operate on individual, professional, and cultural levels (e.g., DeMause, 2002; Herman, 1992; Milburn \& Conrad, 1996). To treat trauma victims successfully, psychologists need to be aware of the ways personal, professional, and social knowing and not knowing about trauma influence trauma studies, awareness for trauma, and recovery trajectories. Psychologists must carefully examine not only the science that informs the understanding of cognitive and emotional adaptations to trauma but also the willingness to address difficult, and often taboo, issues surrounding trauma, interpersonal violence, and society's willingness or refusal to acknowledge their existence and effects.

Awareness for trauma is a complex phenomenon. Both knowing and not knowing about abuse involve several levels of analyses. These levels include cognitive processes such as mem- ory and dissociation, "whole person" processes such as denial, relational dissociation to preserve a relationship, the therapeutic dyad, psychological training and discourse, and societal examination. In addition to being influenced by traumatic responses such as denial, dissociation, and memory impairment, individuals may be aware of the behavioral aspects of traumas they have experienced, such as rape or physical abuse but fail to categorize their experiences as such (e.g., Koss, 1998; Rausch \& Knutson, 1991; Weinbach \& Curtiss, 1986). A lack of awareness for trauma makes subsequent perpetration more likely (Egeland \& Susman-Stillman, 1996), and may contribute to the perpetuation of violence in our society (Milburn \& Conrad, 1996; Miller, 1983).

Another important dimension of awareness for trauma is professional awareness or the lack thereof. Components of professional unawareness may include minimal exposure to trauma studies, psychological traditions that minimally address trauma, and personal and systemic denial of trauma. Many professionals may underestimate the prevalence and impact of trauma and its association with distress and mental disorders. For instance, research demonstrates that most mental health services do not detect childhood trauma histories (Briere \& Zaidi, 1989; Wurr \& Partridge, 1996) primarily because mental health workers often fail to ask about trauma experiences (Read \& Fraser, 1998; Young, Read, Barker-Collo, \& Harrison, 2001). Mainstream approaches to trauma are shaped by traditions within psychology that emphasize single-incident trauma and responses such as fear and anxiety (Brett, 1996; DePrince, 2001). Consequently, psychologists have lower levels of awareness for aspects of trauma such as chronicity, fear, shame, and betrayal.

Personal and professional attitudes toward trauma are also likely to affect levels of awareness and subsequent behavior. For instance, the study of interpersonal violence such as child maltreatment or partner battering may be met with more resistance, even within the professional community, than the study of traumas such as natural disasters, which pose less of a threat to the status quo. In addition, some individuals may believe that discussing traumatic events causes increased distress. Though empirical study shows this is rarely the case (e.g., Griffin, Resick, Waldrop, \& Mechanic, 2003; Newman, Walker, \& 
Gefland, 1999), cultural ideas regarding potential harm may affect research funding and approval (Becker-Blease \& Freyd, 2004).

Acknowledgement of the prevalence and impact of trauma challenges psychological theories that localize dysfunction within the individual while ignoring the contribution of social forces on adjustment (Brett, 1996; Ross, 2000). Such challenges are likely to be related to professional and societal conclusions regarding trauma and its effects. Though empirical study reveals considerable variation in awareness for trauma, the state of this science is often polarized or misrepresented (Freyd, 1998; Pope, 1997). For instance, a large body of research documents the phenomenon of delayed accurate recall for trauma (e.g., Burgess, Hartman, \& Baker, 1995; Cheit, 1998; Corwin \& Olafson, 1997; Herman \& Schatzow, 1987; Sheflin \& Brown, 1996; Sivers, Schooler, \& Freyd, 2002), and the Diagnostic and Statistical Manual of Mental Disorders (4th ed.; DSM$I V$; American Psychiatric Association, 1994) formulation of posttraumatic stress disorder (PTSD) identifies the "inability to recall an important aspect of the trauma" (p. 428) as a common symptom of this disorder. However, some authors still represent delayed recall as highly rare or improbable (e.g., McNally, 2003). Such beliefs persist among many psychologists and laypersons despite the fact that no research supports the implication that such memories are more false than true, and much research supports the premise that unawareness for trauma is a relatively common phenomenon.

Several psychologists (L. Armstrong, 1994; Enns, McNeilly, Corkery, \& Gilbert, 1995; Herman, 1992; McFarlane \& van der Kolk, 1996; Pope \& Brown, 1996) contend that the controversy of delayed recall for traumatic events is likely to be influenced by sexism. Kristiansen, Gareau, Mittleholt, DeCourville, and Hovdestad (1995) found that people who were more authoritarian and who had less favorable attitudes toward women were less likely to believe in the veracity of women's recovered memories for sexual abuse. Those who challenged the truthfulness of recovered memories were more likely to endorse negative statements about women, including the idea that battered women enjoy being abused. McFarlane and van der Kolk (1996) have noted that delayed recall in male combat veterans reported by Myers (1940) and Kardiner (1941) did not generate controversy, whereas delayed re- call in female survivors of intrafamilial child sexual abuse has provoked considerable debate.

Because the study of trauma involves strong emotions, it is especially important for researchers and therapists to evaluate personal reactions and biases that may influence their procedures (e.g., J. G. Armstrong, 1996). Uba (2002) cautions that though data collection and analysis are scientific processes, data interpretation is not. Because trauma research cannot, and ethically should not, use controlled experimental research methods that directly explore responses to trauma, it often relies on correlational analyses or experimental investigations of mechanisms or processes considered similar to those individuals experience during trauma. Though many psychologists are quick to generalize on the basis of laboratory findings regarding cognition and memory for nontraumatic events, the questionable ecological validity of many such findings tempers their applicability to traumatic processes (e.g., Pope, 1997).

An additional challenge in interpreting data regarding traumatic responses involves participant samples. Samples in which trauma has been independently corroborated, such as prosecution samples, provide important data for understanding trauma and its effects. However, generalizing on the basis of such samples may obscure important experiential differences of other traumatized groups related to the recognition and validation of trauma by someone other than the trauma victim. Trauma therapists should cautiously interpret available research by assessing the relevance of a particular study to each individual client's experiences, and plan and deliver treatment most suited for each client.

\section{Phenomena of Knowing and Not Knowing}

Aspects of knowing and not knowing about trauma are related to the quality of the stressor and subsequent environments. It is likely that there are multiple methods through which individuals can keep threatening information from awareness. Similarly, there are many ways individuals may remember information that was not previously available. Research indicates that people who experience trauma may not report trauma (Goodman et al., 2003), inconsistently report trauma or substantially underreport trauma (Fergusson, Horwood, \& Woodward, 2000), deny that trauma was harmful (Egeland \& Sus- 
man-Stillman, 1996; Weinbach \& Curtiss, 1986), and report impaired memory for trauma (Freyd, DePrince, \& Zurbriggen, 2001; Sargant \& Slater, 1941). In addition, traumatic experiences are correlated with alexithymia (Sifneos, 1973), a deficit in individuals' abilities and propensities to identify and describe their emotional experiences (Berenbaum, 1996; Goldsmith \& Freyd, in press; Zlotnick, Mattia, \& Zimmerman, 2001). Culture influences trauma reporting and support for victims. For instance, cultural values that prohibit the discussion of private experiences with strangers outside one's family, or those that emphasize respect and obedience toward one's elders, may prevent abuse disclosure. In addition, empirical studies of maternal support following abuse disclosure reveal ethnocultural differences such as African American mothers being more likely to believe their children than European American or Hispanic mothers. (Kenny \& McEachern, 2000). Gender also influences trauma reporting. In a national survey of adults, men who had experienced childhood sexual abuse (CSA) reported having disclosed the abuse less often than did women (Finkelhor, Hotaling, Lewis, \& Smith, 1990). Weingarten's (2003) model illustrates how dimensions of awareness and empowerment influence the ways we witness trauma. Weingarten explains that unawareness can assuage feelings of helplessness but that becoming aware of trauma can facilitate empowerment. Conversely, changes in perceived power may instigate changes in awareness for trauma. There is a great deal of cultural denial regarding trauma and its effects (DeMause, 2002; Milburn \& Conrad, 1996), which is likely to influence individual levels of awareness.

Several researchers demonstrate the ways people fail to label trauma as such or underreport traumatic experiences. In a sample of 1,526 university students, Rausch and Knutson (1991) found that although participants reported receiving punitive treatment similar to that of their siblings, they were more than twice as likely to identify their siblings' experiences as abusive as they were to label their own in this way. The authors reported that participants were likely to interpret parental treatment toward themselves but not parental treatment toward their siblings as deserved and therefore not abusive. Other studies similarly indicate that those reporting abuse experiences often do not demonstrate a metaconsciousness of having been abused (Goldsmith \&
Freyd, in press; Koss, 1998; Varia \& Abidin, 1999; Weinbach \& Curtiss, 1986). Fergusson et al. (2000) found that among young adults participating in a longitudinal study, about $50 \%$ of those reporting histories of CSA or regular physical punishment at age 18 failed to report these events at age 21. Among those who reported CSA or regular physical punishment at age 21 , about $50 \%$ had failed to report those events at age 18. Data indicated that abuse reporting was unrelated to psychiatric status and that those reporting abuse at one time only did not differ from those who reported abuse consistently. In a similar study, Williams (1994) prospectively investigated traumatic memory by interviewing 136 women 17 years after emergency room visits resulting from CSA. Thirty-eight percent of participants did not report the trauma, though they disclosed other personal information. Such studies reveal inconsistencies in the ways people experience, categorize, and report trauma.

Dissociation appears to contribute to these inconsistencies. The DSM-IV describes dissociation as a separation between processes that are normally integrated. The broadest definitions of dissociation include disconnections from the self, the world, emotions, memories, and others. Such definitions could incorporate alexithymia as one form of dissociation in which individuals have difficulty accessing their own emotional experiences, a relationship that has received some empirical support (e.g., Grabe, Rainermann, Spitzer, Gaensicke, \& Freyberger, 2000). Many studies have confirmed a high incidence of trauma in adults and children with dissociative disorders (e.g., Draijer \& Langeland, 1999; Kisiel \& Lyons, 2001; Macfie et al., 2001; Ogawa, Sroufe, Weinfield, Carlson, \& Egeland, 1997; Putnam, 1996; Zlotnick, et al., 2001). Dissociative tendencies are predicted by trauma chronicity and severity, with multiple forms of abuse and younger ages at onset predicting high levels of dissociation (Stoler, Quina, DePrince, \& Freyd, 2001). In addition, the quality of the stressor influences dissociation. In a community sample of 800 adults, Freyd and Goldberg (2004) found that experiences of sexual abuse and/or physical abuse were more strongly related to dissociation than were nonbetrayal traumas such as accidents.

Dissociation appears to have a complex relation to memory impairment. Laboratory experiments offer some insight into how dissociation operates and may provide knowledge regarding 
the disparate pathways of cognitive development among those who experience trauma. DePrince and Freyd (1999) found an interaction such that low dissociators performed better on a Stroop task under conditions of selected attention, whereas high dissociators performed better under conditions of divided attention. The two groups also showed differences in memory performance depending on the nature of the stimuli. Another study has indicated that individuals may use dissociative skills in response to threatening information. DePrince and Freyd (2001) implemented a directed forgetting task that used both neutral and charged words under conditions of divided attention. High dissociators remembered fewer trauma words and more neutral words compared with low dissociators. Research by DePrince and Freyd therefore suggests that individuals who experience trauma develop divided attention skills and that these skills operate differently depending on the type of information processed.

Such cognitive skills can develop early in life. Becker-Blease, Freyd, and Pears (2004) reported that under conditions of divided attention, abused preschoolers remembered fewer emotionally charged pictures than did children who were not abused. Other studies (e.g., Frankel, Boetsch, \& Harmon, 2000) supported the existence of a relationship between specific cognitive skills and abuse experiences. Dissociation also appears to mediate intergenerational transmission of abuse: Egeland and Susman-Stillman (1996) found that for mothers with childhood abuse, dissociative tendencies and idealization of childhood experiences contributed to abuse toward their own children, and Narang and Contreras (2000) identified dissociation as mediating the relation between individuals' child abuse histories and their potential to physically abuse their own children.

Data indicate that in many ways, traumatic memory seems comparable to nontraumatic memory; that is, it is reconstructive and influenced by social and cognitive factors (Fivush, Hazzard, Sales, Sarfati, \& Brown, 2003). In addition, memory continuity appears to be unrelated to memory accuracy (Freyd, 1998). Several studies demonstrate that chronicity, severity of stress, relationship to perpetrators, and subsequent disclosure are likely to influence memory for trauma. Sargant and Slater (1941) observed the frequency of traumatic amnesia in 1,000 consecutive veteran admissions. Thirty-five percent of those who reported having experienced "severe stress" also reported amnesia. Overall, 14\% of the veterans reported amnesia. In a random sample of Americans, Elliott (1997) reported that $72 \%$ of the 505 individuals who completed a traumatic events survey reported having a traumatic experience. Of these, $32 \%$ reported some degree of delayed recall. The traumatic events that most commonly led to delayed recall were combat exposure, sexual abuse, and witnessing the suicide or murder of a family member. Couacaud (1999) investigated recall for CSA among 112 adult female survivors of CSA. Fifty-nine percent indicated a period of time when they did not remember some or all of the abuse they experienced. Early onset age, chronicity, severity, and abuse perpetrated by a parent all predicted delayed recall. Women report more sexual abuse by family members and abuse that commences at a younger age than do men, who report more sexual abuse by extrafamilial individuals and abuse that commences at older ages (DePrince \& Freyd, 2002). Therefore, it is possible women report more delayed recall than men as an artifact of the moderating impact of gender, age at onset of abuse, and relationship to abuse perpetrator on delayed recall.

Individuals report significantly more memory disturbances for abuse experiences perpetrated by a caregiver than for abuse perpetrated by a noncaregiver (e.g., Freyd, 1996; Freyd et al., 2001). Among 202 participants, Freyd et al. (2001) found that the majority of individuals who reported trauma did not report memory impairment. Among those who did report memory impairment, abuse by a caregiver was a significant factor in memory for abuse, even when accounting for duration and age. Goodman et al. (2003) examined memory for 175 individuals who were all victims of CSA and participated in a criminal prosecution. Twenty-six individuals $(15.5 \%)$ did not report the target incident in an initial phone interview; 12 of these individuals reported the abuse in a subsequent phone interview. Goodman et al. noted that there was a trend for disclosure rates to be higher among individuals who had had more legal experience. Though the authors concluded that forgetting abuse might be uncommon in a prosecution sample, it is noteworthy that 12 individuals still failed to report documented abuse after multiple queries.

Laboratory experiments have indicated that memory is vulnerable to suggestion; however, many of these experiments did not investigate 
memory for trauma. To what extent are such laboratory results generalizable to real traumatic experiences? Pezdek, Finger, and Hodge (1997) demonstrated the importance of event plausibility. Researchers were able to implant false memories of plausible events, such as being lost in a shopping mall, but were unsuccessful at causing participants to form false memories of implausible events, such as receiving an enema or participating in a religious ceremony from a tradition other than their own (Pezdek, Finger, \& Hodge, 1997; Pezdek \& Hodge, 1999). Besides failing to address event plausibility, laboratory experiments may also fail to capture emotions such as fear, shame, and betrayal that are often linked to interpersonal trauma. Another important consideration in interpreting laboratory results is the extent to which authority figures shape individuals' memory and awareness. Just as others can influence a person's memory for events that did not occur, they can influence memory inhibition for events that did occur (Wright, Loftus, \& Hall, 2001). Though no such study would or should receive approval from an ethical review board, Kristiansen, Haslip, and Kelly (1997) pointed out that there are no empirical studies demonstrating that it is possible to instill false memories of abuse.

Differing perspectives on the interpretation of the research presented above, together with psychological, societal, and media trends, have polarized positions regarding traumatic memory into a debate, sometimes called "the recovered memory/false memory debate." An important aspect of the literature on "false memory" is that it actually contains two premises: (a) that it is very uncommon, if not impossible, for individuals to forget and then later remember trauma and (b) that it is possible to implant false memories of trauma (e.g., Loftus \& Ketcham, 1994; McNally, 2003). Psychologists such as McNally (2003) and Loftus and Ketchum (1994) have suggested mechanisms for false memories that include client vulnerability to therapists' suggestions and therapists and clients motivated by financial gain. It is harder to explain why individuals would report impaired memory for trauma in anonymous, self-report methodologies such as those used by Freyd et al. (2001). The American Psychological Association (1995) stated that the news media has sensationalized and overreported false or repressed memories. Beckett (1996) demonstrated that in $199180 \%$ of articles about abuse por- trayed the victim's point of view, but by 1994 $80 \%$ of articles were primarily about allegedly false accusations of abuse.

Research findings regarding the percentage of people who have impaired memory for traumatic experiences vary. We interpret the research presented above as demonstrating that there is a spectrum of awareness for trauma and its effects that is not necessarily unidimensional and that the range of phenomena that impact awareness for abuse includes alexithymia, dissociation, denial, and memory impairment. We recognize the challenges inherent in generalizing on the basis of laboratory experiments, in separating out factors of memory impairment and reluctance to report or acknowledge abuse, and in attempting to discern through research what percentage of people forget trauma and never remember it. Laboratory research aimed at addressing the controversy regarding recall for abuse often is severely limited in its ecological validity and may therefore fail to capture dimensions of shame, fear, and betrayal often inherent in interpersonal trauma. There is no research that unambiguously demonstrates either that it is possible or that it is not possible to create false memories for abuse experiences.

An additional factor that complicates the exploration of awareness of abuse is that conventional wisdom about the very existence and nature of trauma often differs markedly from the reality. For instance, prior to September 11, 2001, I (Rachel E. Goldsmith) told one of my friends what I knew regarding the Taliban's treatment of women. He did not believe me, and said, "If it were that bad, I would know about it." This statement reflects a belief that if trauma is sufficiently upsetting, individuals will be aware of it. Such beliefs may be related to individuals' sense that it is impossible to forget traumatic events. Although false memory psychologists point to therapy sessions as the setting in which people commonly determine that they forgot, and then remembered, abuse. Elliott (1997) found that the majority of people who had forgotten a traumatic event and then remembered it identified the trigger as some form of media presentation, such as a film or a television show. Psychotherapy was the least common trigger for remembering trauma.

\section{Mechanisms and Motivations}

Psychologists describe trauma as overwhelming experiences that exceed an organism's coping 
abilities. Peritraumatic unawareness for some aspects of trauma may reduce demands on personal capacities and enable survival. Most theories and research regarding mechanisms of unawareness incorporate one or more of the following motivations: reducing cognitive dissonance (Festinger, 1957), increasing chances for survival, and adaptation. Cognitive processes that affect awareness for trauma are likely to be impacted by the quality of the stressor. Perhaps the most extreme examples of trauma's impact on cognition and memory occur in the case of repeated or prolonged childhood abuse.

One of humans' first tasks is the formation of an attachment relationship with a primary caregiver. Whereas sensitive caregivers are capable of regulating their children's arousal to some extent (Glaser, 2000), abusive caregiving fails to provide support in regulating affect and demands that children form their own mechanisms to cope with overwhelming arousal. Because children cannot escape or control their home environments, they must adapt to them. Briere's (1992) construct of "abuse dichotomy" proposes that children living in abusive situations are faced with a cognitive conflict: Either their parents' abusive treatment of them is unwarranted and reflects parental inabilities, or it is a justifiable response to their own badness. The former cognition is more threatening because children depend on their parents. By believing that the abusive treatment is deserved, children can maintain the trust in their parents that is necessary for survival, and that may help them retain some sense of control over their environment. Abusive treatment itself strengthens this attribution because it is often accompanied by verbal abuse and other communications indicating that the child is, in fact, bad. Rausch and Knutson (1991) have provided supporting evidence for the presence of such cognitive distortions among abuse survivors.

The development of alexithymia may also facilitate a lack of awareness for prolonged trauma. In situations where trauma is inescapable, it may not be adaptive to develop awareness for one's own emotional experiences. Such awareness could threaten the information isolation that individuals use to cope with their environments. During abuse, victims' experiences, feelings, and memories are consistently ignored or invalidated, which is likely to inhibit emotional awareness. Data demonstrating a link between abuse and alexithymia (Berenbaum, 1996; Goldsmith \&
Freyd, in press) offer support for the presence of a functional relationship between these two phenomena.

Several psychologists have described the ways parental treatment contributes to unawareness. Bowlby (1988) has described the ways some parenting promotes the exclusion of certain emotional experiences from awareness, such as environments in which parents tell their children not to cry or express negative emotions. Children learn that they must deny their own feelings and needs to receive love and care. Similarly, Linehan (1993) described how invalidating environments may create deficits in people's ability to identify and trust their own emotional experiences. Such environments communicate that individuals are wrong in their assessment of their own experience and attribute individuals' experience to traits or characteristics that are unacceptable. Consequently, individuals are not taught to label private experiences accurately, and therefore they have no experience of different ways to modulate their arousal (Linehan, 1993).

Freyd's (1996; Freyd et al., 2001) betrayal trauma theory is based in part on the work of Bowlby and other attachment theorists. This model postulates that children separate abuse experiences from memory and consciousness to maintain the attachment relationships with caregivers that they need to survive. Therefore, abuse by a caregiver fosters a greater degree of amnesia for maltreatment and general unawareness than does abuse by a noncaregiver. Reanalysis of studies examining memory persistence reveals less persistent memories for trauma perpetrated by caregivers than for trauma perpetrated by noncaregivers or for noninterpersonal trauma (Freyd, 1996; Freyd et al., 2001). These findings are consistent with laboratory research demonstrating trauma survivors' tendencies to isolate threatening information from awareness (e.g., DePrince \& Freyd, 2001, 2004).

Coping mechanisms facilitating a lack of awareness, including dissociation, deviate from normally developing systems of attention. Environments that do not allow children to identify or label negative emotional events may reinforce these mechanisms. Such reinforcement may in turn affect memory. Sivers, Schooler, and Freyd (2002) offered an example of a favorite uncle who sexually abuses his nephew but also takes him to a ball game. Recollection for the second 
event is much more likely to be reinforced, whereas the abuse is likely to be accompanied by factors that inhibit recall, such as threats, denial, or pressure not to disclose. In addition, memory research demonstrates that people have poor memories for information for which they do not have a schema or knowledge system (Sivers, Schooler, \& Freyd, 2002). Fivush (1998) reviewed data that suggest young children have more detailed memory for a single novel event than they do for a single episode of a repeated event.

A concept helpful in understanding the ways discussion of events and emotions facilitate awareness is shareability (Freyd, 1983). Shareability theory proposes that the process of sharing information makes information more discrete, stable, and communicable. The construct of shareability has direct bearing on the relative pertinence of memory studies to the phenomenon of delayed recall for abuse. For instance, although Goodman et al. (2003) presented their findings as relevant to the "false memory/recovered memory" debate, the authors stated that the elaborative rehearsal and discussion of the events that occurred during the prosecution process would be likely to strengthen memory for abuse. In addition, corroboration, such as with someone outside the family who acknowledges the abuse, is likely to facilitate later recall (Freyd, 2003b). Finally, shareability is impacted by verbal skills. Fivush (1998) noted that the ability to recall an event verbally is likely to be dependent on the level of verbal ability at the time of its occurrence. Moreover, verbal skills may be impacted by trauma, long after the development of language. Broca's area, the part of the brain responsible for fluid speech production, shows a decrease in oxygen flow during exposure to trauma triggers, which may adversely affect the capacity to articulate traumatic experiences.

The long-term accommodations to chronic trauma described above suggest that such adaptations would prove difficult to reverse. Family abuse occurs simultaneously with individuals' general cognitive development and the development of a sense of self. Trauma victims are also at increased risk for subsequent trauma (e.g., Cloitre, 1998; Desai, Arias, Thompson, \& Basile, 2002; Messman-Moore \& Long, 2000, 2003). Dissociative skills, developed to cope with chronic trauma, could generate subsequent "betrayal blindness" that could lead to further vic- timization. Posttraumatic dissociation is likely to negatively influence subsequent sexual empowerment and decision making in adulthood, including condom use (Kimerling \& Goldsmith, 2000; Zurbriggen \& Freyd, 2004). Traumatized individuals may use substances to promote dissociation, which in turn increases the risk of victimization (e.g., Kimerling \& Goldsmith, 2000).

Societal factors may also promote posttraumatic unawareness. For instance, if an individual is not in an environment that acknowledges trauma and its effects, discussing trauma may be taboo or unfathomable. Societal stigma regarding trauma may inhibit changes to the constriction of cognitive processes described above. In addition, personal unawareness influences not only the perpetuation of trauma but also societal awareness and shareability of trauma.

\section{Psychotherapy}

Psychotherapeutic treatment changes individuals' posttraumatic environment and may thus change awareness for trauma. When therapists provide safe environments for clients' exploration of their experiences, tolerate strong affect, respond empathically, facilitate shareability, and respect clients as the experts on their own memories and feelings, they create a setting vastly different from the individuals' traumatic childhood, and often subsequent, environments (e.g., Gold, 2001). Because during trauma it is usually not safe or possible for individuals to consciously access their emotional reactions or experiences, awareness often emerges after trauma ceases. Therapeutic modalities offer different methods for treating individuals who have experienced trauma. Effective interventions for trauma may include the formulation of a coherent narrative for the experience (Foa, Molnar, \& Cashman, 1995). Many psychoanalytic approaches emphasize creating awareness for childhood trauma (e.g., Miller, 1983). Other effective approaches may draw on interventions from cognitivebehavioral (e.g., Cohen, Mannarino, Berliner, \& Deblinger, 2000), behavioral (e.g., van der Kolk \& McFarlane, 1996), or dialectical behavioral (Linehan, 1993) therapies. Whereas all of these techniques address trauma-related affect, therapeutic practices vary in the extent to which they promote awareness of the relevance of past traumatic experiences to current psychosocial functioning. 
Trauma is a topic rarely included beyond the most cursory level in most therapists' training (Courtois, 2002). Because it is not usually the trauma itself that causes individuals to seek help, rather it is often the distress from its subsequent effects and interpretation, most abuse survivors seek therapy because of complaints about themselves, their interpersonal relationships (Briere, 2002), or as a result of depression (e.g., Berliner \& Elliott, 1996). Assessors miss many trauma experiences, in part because assessment methods such as the Structured Clinical Interview for $D S M-I V$ Axis I disorders (First, Spitzer, Gibbon, $\&$ Williams, 1997) use DSM-IV PTSD definitions geared toward single-incident traumas perceived as life-threatening. Clinician discomfort, lack of time and resources, or a dearth of training regarding trauma are some of the reasons healthcare providers fail to ask about trauma (Read \& Fraser, 1998). Awareness for trauma can assuage posttraumatic distress and reduce the possibility of intergenerational transmission; disclosing trauma and creating coherent narratives of traumatic experiences facilitates mental and physical health (e.g., Pennebaker, Kiecolt-Glaser, \& Glaser, 1988). However, trauma symptoms such as avoidance and dissociation may prevent both clients and therapists from accurately gauging the effects of trauma.

Some therapists may explicitly challenge or reinterpret the events reported by clients, whereas others more subtly provide support and environments that can enable clients to instigate shifts in their awareness. Weinbach and Curtiss (1986) have raised the ethical issue of whether to make abuse victims aware of the abusiveness of their treatment. Given the research linking unawareness to subsequent abusive parenting (Egeland \& Susman-Stillman, 1996), we feel it would be unethical not to advocate for client awareness. We recognize that changing awareness for trauma is a difficult process that should proceed according to individual levels of comfort. Changing abuse perceptions and attributions may itself engender a period of psychological distress. Ultimately, however, psychological education regarding the prevalence and effects of trauma may facilitate awareness and counter feelings of shame and isolation.

Those who believe recovered accurate memories are rare or nonexistent advocate psychotherapy that minimizes past events (Pope \& Vasquez, 1998). Many prominent models of psychotherapy, such as cognitive-behavioral therapy
(Beck, 1995), emphasize functioning in the present. Beck (1995) described reasons to emphasize a client's past experiences, including positive client expressions regarding helpfulness of therapy or therapist belief that it is important for the therapeutic dyad to understand the development of dysfunctional beliefs. Such circumstances could vary widely according to client and therapist awareness and preferences.

Several therapeutic modalities and techniques promote increased levels of awareness and functioning following trauma. Cognitive focused therapy appears effective for trauma survivors (e.g., Cohen et al., 2000). Cognitive techniques emphasize awareness of thought processes and their relations to affect and appear to be an important part of successful therapies for trauma survivors. Folette, Rozek, and Abueg (1998) described how a cognitive content-oriented approach focuses on the ways in which negative beliefs can cause distress, maintain symptoms, reinforce ideas regarding the dangerousness of the world, engender less support from others, and exacerbate self-blame, guilt, and low self-efficacy.

In addition, there are several aspects of cognitive-behavioral therapy that indicate it would be a helpful approach for survivors of chronic trauma. The therapy aims to identify "core beliefs" that are "global, overgeneralized, and absolute" (Folette et al., 1998, p. 167). Core beliefs stem from childhood events and are maintained by selectively acknowledging data that support them and by minimizing data that do not. Common core beliefs among survivors of protracted child abuse, for example, include assessments of oneself as hopeless or unlovable. Understanding the etiology and development of dysfunctional beliefs may help assuage the self-criticism so often present in those who have experienced chronic trauma.

Van der Kolk and McFarlane (1996) described behavioral approaches based on theories of classical and operant conditioning that can inform treatment with survivors of trauma. A highly stressful event leads to arousal and associated reactions. Subsequently, previously neutral stimuli (conditioned stimuli; CS) can soon elicit related responses on their own (conditioned responses; CRs), such as distress, fear, and horror.

Briere (2002) extended models of conditioning to include "conditioned emotional responses" (CERs), relational schema based on early interactions with caregivers. Often, survivors will en- 
gage in behavior such as substance abuse or selfinjury to escape or avoid CS or CRs; when these behaviors succeed, they are reinforced. Healing occurs when therapist responses to CS deviate from victims' expected responses. Within the context of a therapeutic relationship threatening information is met with empathy and care, a response that weakens relations between traumatic memories and CERs. Similarly, the conceptualization underlying Linehan's (1993) dialectical behavior therapy (DBT) highlights how lack of emotional awareness results from invalidating environments. Central goals of DBT, therefore, include emotion regulation, development of trust, and validation of emotional experience. According to Linehan, to change response patterns therapists need to activate CRs but simultaneously provide therapeutic environments of safety, empathy, and shareability, features that are incompatible with the pathological elements of clients' relational and emotional structures.

Functional analysis, in which behavior is understood by assessing its purpose rather than categorized exclusively by its observable characteristics, similarly emphasizes awareness for the relations between past experiences and current behaviors (Naugle \& Folette, 1998). Folette, Rozek, and Abueg (1998) have advocated adopting a contextual-ecological perspective whereby symptoms and problems must be evaluated in the historical and current environmental and interpersonal contexts in which they developed and are maintained. Deficits in awareness, impaired emotional awareness, and distorted general cognitions about self and the world may be symptoms that were once functional defenses against the debilitating impact of living in traumatic circumstances. When trauma is endemic to the environments in which they are reared, clients may have sacrificed awareness to maintain attachment relationships, denied trauma for fear of retribution from a perpetrator, or been unable to reconcile loving feelings toward a perpetrator with awareness of the maltreatment that they experienced.

Functional analysis can also address ways that posttraumatic symptoms such as avoidance or intrusion of memories and feelings may be maintained. For instance, trauma often precedes substance use disorders (Stewart \& Conrod, 2003). Though there are currently no controlled trials to demonstrate the most effective processes for treating co-occurring substance use disorders and trauma symptoms, several are currently underway that should inform treatment (Ouimette, Moos, \& Brown, 2003). Substance use treatment with trauma survivors is more effective when it incorporates treatment for trauma symptoms than when it addresses substance use alone (Kimerling \& Goldsmith, 2000), suggesting that functional analyses of posttraumatic behavior may help to optimize treatment.

Unawareness of trauma and its effects may decrease the likelihood that individuals present for treatment. Indeed, Erickson and Egeland (1996) noted that individuals most in need of services may be the least likely to volunteer for them. Obstacles to effective intervention with survivors of trauma may include posttraumatic symptoms themselves, such as dissociation and avoidance. Dissemination of information to facilitate symptom awareness, prevalence of childhood maltreatment, and treatment availability is therefore crucial to treating those who need it. Other research highlights potential costs that result from awareness. Individuals who experience treatment itself as abusive may feel guilt from questioning the behavior and intentions of their own family or may be targets of blame by family members for disrupting silence regarding trauma. Such responses may feel as painful as the trauma itself (Root, 1992). However, individuals who acknowledge abuse may succeed in reversing the abuse dichotomy (Briere, 1992) and may be less likely to see themselves as bad and deserving of maltreatment. Moreover, knowing about abuse may augment awareness regarding one's own strength and survivorship.

Traditional therapies used for trauma have focused primarily on the problems of fear, anxiety, and hyperarousal. The numbing, dissociation, and avoidance so prevalent in cases of betrayal trauma have been more difficult to dispel through the use of traditional therapies. Freyd (1999) noted that "the potential to heal internal disconnection is most fully realized in the context of what was broken in the first place - an intimate and trusting relationship" (p. 6). To the extent that individuals are suffering from the consequences of betrayal traumas, "relational therapy" thus offers a promising therapeutic approach (Birrell \& Freyd, in press). In relational therapy, a focus on listening, mutuality, compassion, ethics, and community may prove to be a powerful antidote to betrayal.

A thorough understanding of trauma, its ef- 
fects, and its potential to influence treatment dynamics is essential to the therapy of trauma victims. For instance, research indicating that dissociation is linked to the creation of special cognitive skills (e.g., DePrince \& Freyd, 1999) has clinical implications. If traumatized individuals use skills such as divided attention to help control the flow of information into consciousness, what appears as a self-destructive tendency to create a chaotic environment may actually represent an adaptive self-protective maneuver. Therapists would be most helpful if they were to understand and appreciate these cognitive skills and their functions, rather than thinking of them exclusively as indicators of maladjustment. Indeed, the habitual creation of an environment that supports divided attention may even have adaptive consequences depending on the demands of the situation, and individuals with these skills might benefit from finding productive uses for their abilities (such as employment opportunities in which divided attention abilities are valued).

Although awareness of trauma in the lives of clients and patients in the mental health system is important, it is also important to ensure that the role of trauma is not overemphasized. Naugle and Folette (1998) caution trauma therapists to guard against common errors in judgment. For instance, in the error of parsimony, clinicians try to identify a minimal set of causal explanations. Therapists who focus on trauma may limit assessment of other conditions and experiences. Many psychologists assert that it is important to avoid blaming the victim (Linehan, 1993; Root, 1992) and to avoid falling into the role of either the rescuer or the perpetrator (Linehan, 1993; Ross, 2000), as these dynamics reinforce power differentials intrinsic to the pathology of clients' early experiences. Therapists and clients should collaboratively determine processes and contents. Therapists and clients should collaboratively determine the pace and content of psychotherapy and together consider potential iatrogenic mechanisms such as avoidance. By offering trauma victims choice, control, empathy, and respect, the therapist's behavior contradicts aspects of the traumatic experiences and facilitates healing, awareness, and empowerment.

\section{Conclusions and Future Directions}

Trauma research and treatment raises challenges not only for psychologists and clients but for all of society. Trauma study presents an epistemological challenge to dominant psychological theory because it highlights the role of context in the etiology and maintenance of pathology. As psychologists, we are ensconced in a diagnostic system that frequently pathologizes individuals rather than explicitly acknowledging the ways problems in society, such as violence, may contribute to dysfunction. Psychologists themselves must attend to the functions and effects of their own unawareness. For instance, van der Kolk and McFarlane (1996) have hypothesized that the search for predisposing factors for PTSD likely stems from psychologists' need to deny that otherwise well-adjusted people can encounter stressful situations beyond their coping capabilities. Psychologists may also downplay trauma and its effects so as not to threaten the status quo of psychology or to maintain necessary relationships with supervisors or colleagues whose treatment models do not recognize the impact of trauma on psychological adaptation. Our treatment settings may only allow for a limited number of sessions, which may cause us to refrain from addressing trauma if we feel we do not have adequate time for quality treatment. In both clinical and research settings, one can get the impression that trauma, like multiculturalism (see Hayes, 1995), threatens extant psychological conceptualizations by introducing additional levels of analysis. Considering trauma "opens up a whole new can of worms." However, the worms are still in the can, whether or not it is opened! Failing to consider all relevant aspects of psychological experience constitutes a disservice to clients, science, and society.

If effectively disseminated, the existing psychological research has the potential to greatly increase professional and public awareness regarding trauma. Despite the continued growth of the empirical, clinical, and theoretical literature on trauma in the last few years, there is still much that needs to be done. Freyd et al. (2001) have advocated that more prospective studies with independent corroboration of abuse should be conducted, but they cautioned that although this method decreases the likelihood of false positives (i.e., memories of abuse that did not actually occur), it is vulnerable to false negatives (i.e., concluding that no abuse occurred, when in fact it did). Freyd (2003a) proposed that goals for future research should include the execution of studies that address potential confounds to continuous 
recall, such as being believed, articulating abuse experiences, or having the event discovered by another person. She identified three important groups to research in combined samples: a group with simultaneous corroboration of abuse, such as legal or medical records; a group with corroboration following abuse, such as a perpetrator confession; and a group with both contemporaneous and subsequent documentation, such as prosecution experience.

Empirical investigations that reveal to what extent exploring client trauma helps the management of current thoughts, feelings, and behaviors are also needed. Such studies can inform professionals and society when they are conscientiously reported and disseminated. At this point, we are unaware of psychotherapy outcome studies for victims of trauma that use random assignment to compare therapy that does not focus on trauma with therapy that does focus on trauma. Such studies should use long-term follow-up methods to ascertain which therapies most strongly improve long-term psychological functioning. Outcome studies regarding effective treatment for different kinds of trauma are needed to guide the work of clinicians and psychologists interested in healing processes.

Over the past 20 years, considerable research has demonstrated the range of responses to trauma. However, this research has not been clearly disseminated. For example, the American Psychological Association provides Internet information regarding memory for trauma, but (as of this writing) has not updated that information to include research on this topic that has occurred since 1995. Most theory and research regarding behavioral treatment for trauma emphasizes fear and anxiety; however, other emotions, such as guilt and shame, may be just as strongly implicated in maintaining maladaptive functioning (e.g., Irwin, 1998). The current DSM-IV depiction of trauma focuses on single-incident trauma and on fear and anxiety responses, even though research has identified qualitative differences in sequelae to traumatic experiences as a function of chronicity and degree of interpersonal betrayal involved in the trauma. For example, being involved in a single major motor vehicle accident is very different in many ways from being the victim of prolonged sexual abuse by a parent. DSM$I V$ diagnoses must reflect the current state of psychological research and incorporate the expertise of the trauma task forces it commissions. Diag- noses should be expanded to take into account the effects of chronic trauma on systems of self-regulation and emotional awareness, incorporate a variety of emotional responses to trauma, and account for the frequent presence of cooccurring conditions such as depression and substance use and the ways these may interact with traumatic experience and posttraumatic symptoms.

Societal awareness regarding trauma affects victim and therapist awareness as well as societal discourse on trauma. The media most likely have great influence over this awareness, though such effects have yet to be thoroughly researched. For instance, Folette et al. (1998) have noted that on television and in movies, victims of violent attacks usually carry on as if nothing has occurred, which can mislead trauma victims about the intensity of the commonly occurring reactions to these types of events. Conversely, the period of 2001-2003 constituted a time of prolific reporting regarding sexual abuse in the Catholic Church that, interestingly, fueled public and journalistic outrage aimed both at the extent of sexual abuse and at the silence and cover-up. Though discourse regarding these events was indeed important, it may have obscured attention to the fact that sexual abuse by family members remains much more common than abuse by clergy. It is possible that public preference for stories regarding victimization of large groups of people decreases media attention to isolated but more commonplace types of incidents.

It is important to attend to language and rhetoric and the ways these shape professional and public awareness. Labels such as the "borderline personality" diagnosis in the DSM-IV encourage psychologists to pathologize victims to a greater extent than the ICD-9 label, "enduring personality changes due to trauma" (Brown, 1992). Neither "false memory syndrome" nor "recovered memory therapy" has empirical support as a syndrome or therapeutic approach, but such terms may affect societal awareness for trauma. For instance, Campbell (2003) reviewed the ways the "recovered memory-false memory" debate has generated doubt regarding all trauma victims' memories and experiences, including those with continuous memory. Furthermore, extended debate about the veridicality of memories of abuse deflects attention from the issue of which types of therapy are most effective in helping survivors 
heal (Gold, 2001). Finally, we must consider the possibility that an overemphasis on trauma perpetrated by outsiders, such as terrorists from other countries, may prevent focus on trauma or betrayal perpetrated by citizens of our own country or within the victim's own family. Miller (1983) has argued that the unacceptability of awareness for parental maltreatment and its accompanying emotions results in displaced "acceptable" negative feelings and actions toward other persons, groups, or nations.

These are issues that are difficult to examine with empirical rigor because neither exposure to traumatic experiences nor assignment of individuals to societies that acknowledge and discuss trauma can be randomized. Our own impression is that the American culture is in a period of relative quiet regarding betrayal trauma. Although there is a wealth of research documenting the negative effects of trauma, a highly visible faction of psychologists persist in downplaying its deleterious effects and in discounting the extent of suffering that results from trauma. Perhaps the period of increased professional and public understanding of trauma and its effects that took place in the 1990s was too threatening for professionals and the larger society to accept and assimilate. We do not consider it a tenable position that trauma justifies criminality, perpetration of abuse, or a decrease in personal responsibility. However, it is precisely because denial and dissociation contribute to the reenactment of violence that we must insist on awareness for personal and societal trauma. Any climate that explicitly or implicitly reduces discussion about abuse awareness and abuse accuracy increases the secrecy and unawareness about abuse, thus perpetuating its continuation.

Herman (1992) stated that the opposing impulses of both the psychological and lay community to deny the reality of trauma on one hand and to attend to the truth and importance of traumatic experiences on the other form a basic dialectic of trauma psychology that affects both victims and therapists. To conduct the best quality scientific investigation of traumatic phenomena and to provide optimal treatment to survivors, unflinching and consistent focus on trauma is required. It remains to be seen whether our profession and our society have the courage and determination to rise to this challenge.

\section{References}

American Psychiatric Association. (1994). Diagnostic and statistical manual of mental disorders (4th ed.). Washington, DC: Author.

American Psychological Association. (1995). Questions and answers about memories of childhood abuse. Retrieved August 15, 2003, from http://www.apa.org/pubinfo/ mem.html

Armstrong, J. G. (1996). Emotional issues and ethical aspects of trauma research. In E. B. Carlson, (Ed), Trauma research methodology (pp. 174-187). Lutherville, MD: Sidran Press.

ARMSTRONG, L. (1994). Rocking the cradle of sexual politics: What happened when women said incest. Reading, MA: Addison-Wesley.

BeCK, J. S. (1995). Cognitive therapy: Basics and beyond. New York: Guilford Press.

Becker-Blease, K. A., \& Freyd, J. J. (2004, August). Why not ask about abuse? Beliefs that hold researchers back. Paper presented at the 112th Annual Conference of the American Psychological Association, Honolulu, HI.

Becker-Blease, K. A., Freyd, J. J., \& Pears, K. C. (2004). Preschoolers' memory for threatening information depends on trauma history and attentional context: Implications for the development of dissociation. Journal of Trauma and Dissociation, 5, 113-131.

BeCKetT, K. (1996). Culture and the politics of signification: The case of child sexual abuse. Social Problems, 43, 57-76.

Berenbaum, H. (1996). Childhood abuse, alexithymia, and personality disorder. Journal of Psychosomatic Research, 41, 585-595.

Berliner, L., \& Elliott, D. M. (1996). Sexual abuse of children. In J. Briere, L. Berliner, J. A. Bulkley, C. Jenny, $\&$ T. Reid (Eds.), The American Professional Society on the Abuse of Children handbook on child maltreatment. Thousand Oaks, CA: Sage.

Bernstein, E. M., \& Putnam, F. W. (1986). Development, reliability, and validity of a dissociation scale. Journal of Nervous \& Mental Disease, 174, 727-735.

BirRell, P. J., \& Freyd, J. J. (in press). Betrayal trauma: relational models of harm and healing. Journal of Trauma Practice.

BRETT, E. A. (1996). The classification of posttraumatic stress disorder. In B. A. van der Kolk, A. C. McFarlane, \& L. Weisaeth (Eds.), Traumatic stress: The effects of overwhelming experience on mind, body, and society (pp. 117-128). New York: Guilford Press.

BRIERE, J. (1992). Child abuse trauma: Theory and treatment of the lasting effects. Newbury Park, CA: Sage.

BRIERE, J. (2002, June 6). Not just PTSD: The complexity of posttraumatic states. Paper presented at the First Annual Conference on Trauma, Attachment, and Dissociation, Vancouver, British Columbia, Canada.

BRIERE, J., \& ZAIDI, L. Y. (1989). Sexual abuse histories and sequelae in female psychiatric emergency room patients. American Journal of Psychiatry, 146, 1602-1606.

Bowlby, J. (1988). A secure base: Parent-child attachment and healthy human development. New York: Basic Books.

Brown, L. S. (1992). A feminist critique of the personality disorders. In L. S. Brown \& M. Ballou (Eds.), Personality and psychopathology: Feminist reappraisals. New York: Guilford Press.

Burgess, A. W., Hartman, C. R., \& Baker, T. (1995). 
Special Issue: Knowing and Not Knowing About Trauma

Memory presentations of child sexual abuse. Journal of Psychosocial Nursing, 33, 9-16.

CAMPBELL, S. (2003). Relational remembering. Lanham, MD: Rowan \& Littlefield.

CheIT, R. E. (1998). Consider this, skeptics of recovered memory. Ethics \& Behavior, 8, 141-160.

Chu, J. A., \& Dill, D. L. (1990). Dissociative symptoms in relation to childhood physical and sexual abuse. American Journal of Psychiatry, 147, 887-892.

Cloitre, M. (1998). Sexual revictimization: Risk factors and prevention. In V. M. Folette, J. I. Ruzek, \& F. R. Abueg (Eds.), Cognitive-behavioral therapies for trauma (pp. 278-304). New York: Guilford Press.

Cohen, J. A., Mannarino, A. P., Berliner, L., \& Deblinger, E. (2000). Trauma-focused cognitive therapy for children and adolescents: An empirical update. Journal of Interpersonal Violence, 15, 1202-1223.

CoRwin, D. L., \& Olafson, E. (1997). Videotaped discovery of a reportedly unrecallable memory of child sexual abuse: Comparison with a childhood interview videotaped 11 years before. Child Maltreatment, 2, 91-112.

CouACAud, K. L. (1999). Recall of childhood sexual abuse: Abuse characteristics and clarity of memory. Dissertation Abstracts International, 59(7), 3686B. (UMI No. AAM9839235)

Courtois, C. A. (2002). Traumatic stress studies: The need for curricula inclusion. Journal of Trauma Practice, 1, 33-58.

DeMause, L. (2002). The emotional life of nations. New York: Karnac.

DePrince, A. P. (2001). Trauma and posttraumatic responses: An examination of fear and betrayal. Dissertation Abstracts International, 62(6), 2953B. (UMI No. AAI3018361)

DePrince, A. P., \& Freyd, J. J. (1999). Dissociative tendencies, attention, and memory. Psychological Science, 10, 449-452.

DePrince, A. P., \& Freyd, J. J. (2001). Memory and dissociative tendencies: The roles of attentional context and word meaning in a directed forgetting task. Journal of Trauma and Dissociation, 2, 67-82.

DePrince, A. P., \& Freyd, J. J. (2002). The intersection of gender and betrayal in trauma. In R. Kimerling, P. Ouimette, \& J. Wolfe (Eds.), Gender and PTSD (pp. 98-113). New York: Guilford Press.

DePrince, A. P. \& Freyd, J. J. (2004). Forgetting trauma stimuli. Psychological Science, 15, 488-492.

Desai, S., Arias, I., Thompson, M. P., \& Basile, K. C. (2002). Childhood victimization and subsequent adult revictimization assessed in a nationally representative sample of women and men. Violence \& Victims, 17, 639-653.

DEVRIES, M. W. (1996). Trauma in cultural perspective. In B. A. van der Kolk, A. C. McFarlane, \& L. Weisaeth (Eds.), Traumatic stress: The effects of overwhelming experience on mind, body, and society (pp. 3-23). New York: Guilford Press.

DraiJer, N., \& LANGELAND, W. (1999). Childhood trauma and perceived parental dysfunction in the etiology of dissociative symptoms in psychiatric inpatients. American Journal of Psychiatry, 156, 379-385.

Egeland, B., \& Susman-Stillman, A. (1996). Dissociation as a mediator of child abuse across generations. Child Abuse \& Neglect, 20, 1123-1132.

ElliotT, D. M. (1997). Traumatic events: Prevalence and delayed recall in the general population. Journal of Consulting and Clinical Psychology, 65, 811-820.

Enns, C. Z., McNeilly, C., Corkery, J., \& Gilbert, M. (1995). The debate about delayed memories of child sexual abuse: A feminist perspective. The Counseling Psychologist, 23, 181-279.

Erickson, M. F., \& Egeland, B. (1996). Child neglect. In J. Briere, L. Berliner, J. A. Bulkley, C. Jenny, \& T. Reid (Eds.), The American Professional Society on the Abuse of Children handbook on child maltreatment. Thousand Oaks, CA: Sage.

Fergusson, D. M., Horwood, L. J., \& Woodward, L. J. (2000). The stability of child abuse reports: A longitudinal study of the reporting behavior of young adults. Psychological Medicine, 30, 529-544.

FESTINGER, L. (1957). A theory of cognitive dissonance. Palo Alto, CA: Stanford University Press.

Finkelhor, D., Hotaling, G., Lewis, I. A., \& Smith, C. (1990). Sexual abuse in a national survey of adult men and women: Prevalence, characteristics, and risk factors. Child Abuse \& Neglect, 14, 19-28.

First, M. B., Spitzer, R. L., Gibbon, M., \& Williams, J. B. W. (1997). Structured Clinical Interview for DSM-IV Axis I Disorders. Washington, DC: American Psychiatric Press.

Fivush, R. (1998). Children's recollections of traumatic and nontraumatic events. Development and Psychopathology, 10, 699-716.

Fivush, R., Hazzard, A., Sales, J. M., Sarfati, D., \& BRown, T. (2003). Creating coherence out of chaos? Children's narratives of emotionally positive and negative events. Applied Cognitive Psychology, 17, 1-19.

Foa, E. B., Molnar, C., \& Cashman, L. (1995). Change in rape narratives during exposure therapy for posttraumatic stress disorder. Journal of Traumatic Stress, 8, 675-690.

Folette, V. M., RUzeK, J. I., \& Abueg, F. R. (1998). A contextual analysis of trauma: Theoretical considerations. In V. M. Follette, J. I. Ruzek, \& F. R. Abueg (Eds.), Cognitive-behavioral therapies for trauma. New York: Guilford Press.

Frankel, K. A., Boetsch, E. A., \& Harmon, R. J. (2000). Elevated picture completion scores: A possible indicator of hypervigilance in maltreated preschoolers. Child Abuse \& Neglect, 24, 63-70.

FREYD, J. J. (1983). Shareability: The social psychology of epistemology. Cognitive Science, 7, 191-210.

FreYd, J. J. (1996). Betrayal trauma: The logic of forgetting abuse. Cambridge, MA: Harvard University Press.

FREYD, J. J. (1998). Science in the memory debate. Ethics \& Behavior, 8, 101-113.

FREYD, J. J. (1999). Blind to betrayal: New perspectives on memory for trauma. The Harvard Mental Health Letter, 15(12), 4-6.

FREYD, J. J. (2003a). Commentary: Response to 17 February 2003 media reports on Loftus' Bugs Bunny study. Retrieved August 31, 2003, from http://dynamic.uoregon.edu/jjf/ bugs.html

FREYD, J. J. (2003b). Memory for abuse: What can we learn 
from a prosecution sample? Journal of Child Sexual Abuse, 12, 97-103.

Freyd, J. J., DePrince, A., \& Zurbriggen, E. (2001). Selfreported memory for abuse depends on victim-perpetrator relationship. Journal of Trauma and Dissociation, 2, 5-16.

Freyd, J. J., \& GoldberG, L. R. (2004, November). Gender difference in exposure to betrayal trauma. Presented at the 20th annual meeting of the International Society for Traumatic Stress Studies, New Orleans, LA.

GLASER, D. (2000). Child abuse and neglect and the brain: A review. Journal of Child Psychology and Psychiatry and Allied Disciplines, 41, 97-116.

GoLD, S. N. (2001). Conceptualizing child sexual abuse in interpersonal context: Recovery of people, not memories. Journal of Child Sexual Abuse, 10, 51-71.

GoldSMITH, R., \& FREYD, J. J. (in press). Awareness for emotional abuse. Journal of Emotional Abuse.

Goodman, G. S., Quas, J. A., Edelstein, R. S., AleXander, K. W., Redlich, A. D., Cordon, I. M., \& Jones, D. P. H. (2003). A prospective study of memory for child sexual abuse: New findings relevant to the repressed/lost memory controversy. Psychological Science, 14, 113-118.

Grabe, H. J., Rainermann, S., Spitzer, C., Gaensicke, M., \& Freyberger, H. J. (2000). The relationship between dimensions of alexithymia and dissociation. Psychotherapy and Psychosomatics, 69, 128-131.

Griffin, M. G., Resick, P. A., Waldrop, A. E., \& Mechanic, M. B. (2003). Participation in trauma research: Is there evidence of harm? Journal of Traumatic Stress, 16, 221-227.

HAYES, P. A. (1995). Multicultural applications of cognitivebehavioral therapy. Professional Psychology: Research and Practice, 26, 309-315.

Herman, J. L. (1992). Trauma and recovery. New York: Basic Books.

Herman, J. L., \& Schatzow, E. (1987). Recovery and verification of memories of childhood sexual trauma. Psychoanalytic Psychology, 4, 1-14.

IRWIN, H. J. (1998). Affective predictors of dissociation II: Shame and guilt. Journal of Clinical Psychology, 54, 237-245.

KARDINER, A. (1941). The traumatic neurosis of war. New York: Hoeber.

Kenny, M. C., \& McEachern, A. G. (2000). Racial, ethnic, and cultural factors of childhood sexual abuse: A selected review of the literature. Clinical Psychology Review, 20, 905-922.

Kimerling, R., \& Goldsmith, R. (2000). Links between exposure to violence and HIV-infection: Implications for substance abuse treatment with women. Alcoholism Treatment Quarterly, 18, 61-69.

Kisiel, C. L., \& Lyons, J. S. (2001). Dissociation as a mediator of psychopathology among sexually abused children and adolescents. American Journal of Psychiatry, 158, 1034-1039.

Koss, M. P. (1998). Hidden rape: Sexual aggression and victimization in a national sample of students in higher education. In M. E. Odem \& J. Clay-Warner (Eds.), Confronting rape and sexual assault: Vol. 3. Worlds of women (pp. 51-69). Wilmington, DE: SR Books.

Kristiansen, C. M., Gareau, C., Mittleholt, J., DeCourVILLE, N. H., \& Hovdestad, W. E. (1995, August). Socialpsychological factors sustaining the recovered memory de- bate. Paper presented at the 103rd Annual Conference of the American Psychological Association, New York.

Kristiansen, C. M., Haslip, S. J., \& Kelly, K. D. (1997) Scientific and judicial illusions of objectivity in the recovered memory debate. Feminism \& Psychology, 7, 39-45.

LineHAN, M. M. (1993). Cognitive-behavioral treatment of borderline personality disorder. New York: Guilford Press.

Loftus, E. F., \& KetchaM, K. (1994). The myth of repressed memory: False memories and allegations of sexual abuse. New York: St. Martin's Press.

Macfie, J., Cicchetti, D., \& Toth, S. L. (2001). The development of dissociation in maltreated preschool-aged children. Development and Psychopathology, 13, 233-254.

McFarlane, A. C., \& VAN DER KolK, B. (1996). Trauma and its challenge to society. In B. A. van der Kolk, A. C. McFarlane, \& L. Weisaeth (Eds.), Traumatic stress: The effects of overwhelming experience on mind, body, and society (pp. 417-440). New York: Guilford Press.

McNally, R. J. (2003). Remembering trauma. Cambridge, MA: Belknap Press/Harvard University Press.

Messman-Moore, T. L., \& Long, P. J. (2000). Child sexual abuse and revictimization in the form of adult sexual abuse, adult physical abuse, and adult psychological maltreatment. Journal of Interpersonal Violence, 15, 489-502.

Messman-Moore, T. L., \& Long, P. J. (2003). The role of childhood sexual abuse sequelae in the sexual revictimization of women: An empirical review and theoretical reformulation. Clinical Psychology Review, 23, 537-571.

Myers, C. S. (1940). Shell shock in France 1914-1918. Cambridge, England: Cambridge University Press.

Milburn, M. A., \& ConRad, S. D. (1996). The politics of denial. Cambridge, MA: MIT Press.

Miller, A. (1983). For your own good: Hidden cruelty in childrearing and the roots of violence. New York: Farrar.

NARANG, D. S., \& Contreras, J. M. (2000). Dissociation as a mediator between child abuse history and adult abuse potential. Child Abuse \& Neglect, 24, 653-665.

NAugle, A. E., \& Folette, W. C. (1998). A functional analysis of trauma symptoms. In V. M. Follette, J. I. Ruzek, \& F. R. Abueg (Eds.), Cognitive-behavioral therapies for trauma (pp. 48-73). New York: Guilford Press.

Nelson, C. A., \& Carver, L. J. (1998). The effects of stress and trauma on brain and memory: A view from developmental cognitive neuroscience. Development and Psychopathology, 10, 793-809.

Newman, E., Walker, E. A., \& Gefland, A. (1999). Assessing the ethical costs and benefits of trauma-focused research. General Hospital Psychiatry, 21, 187-196.

Ogawa, J. R., Sroufe, L. A., Weinfield, N. S., Carlson, E. A., \& Egeland, B. (1997). Development of the fragmented self: Longitudinal study of dissociative symptomatology in a nonclinical sample. Development and Psychopathology, 9, 855-879.

Ouimette, P., Moos, R. H., \& Brown, P. J. (2003). Substance use disorder-posttraumatic stress disorder comorbidity: A survey of treatments and proposed practice guidelines. In P. Ouimette \& P. J. Brown (Eds.), Trauma and substance abuse: Causes, consequences, and treatment of comorbid disorders. (pp. 91-110). Washington, DC: American Psychological Association.

Pennebaker, J. W., Kiecolt-Glaser, J. K., \& Glaser, R. (1988). Disclosure of traumas and immune function: Health implications for psychotherapy. Journal of Consulting and Clinical Psychology, 56, 239-245. 
Pezdek, K., Finger, K., \& Hodge, D. (1997). Planting false childhood memories: The role of event plausibility. Psychological Science, 8, 437-441.

Pezdek, K., \& Hodge, D. (1999). Planting false childhood memories in children: The role of event plausibility. Child Development, 70, 887-895.

Pope, K. S. (1997). Science as careful questioning: Are claims of a false memory syndrome epidemic based on empirical evidence? American Psychologist, 52, 997-1006.

Pope, K. S., \& Brown, L. S. (1996). Recovered memories of abuse: Assessment, therapy, forensics. Washington, DC: American Psychological Association.

Pope, K. S., \& VASQUeZ, M. J. T. (1998). Ethics in psychotherapy and counseling: A practical guide. San Francisco: Jossey-Bass.

Putnam, F. W. (1996). Child development and dissociation. Child \& Adolescent Psychiatric Clinics of North America, 5, 285-301.

Rausch, K., \& Knutson, J. F. (1991). The self-report of personal punitive childhood experiences and those of siblings. Child Abuse \& Neglect, 15, 29-36.

READ, J., \& Fraser, A. (1998). Abuse histories of psychiatric inpatients: To ask or not to ask? Psychiatric Services, 49, 355-359.

Root, M. P. P. (1992). Reconstructing the impact of trauma on personality. In L. S. Brown \& M. Ballou (Eds.), Personality and psychopathology: Feminist reappraisals (pp. 229-265). New York: Guilford Press.

Ross, C. A. (2000). The trauma model: A solution to the problem of comorbidity in psychiatry. Richardson, TX: Manitou Communications.

Sargant, W., \& Slater, E. (1941). Amnesic syndromes in war. Proceedings of the Royal Society of Medicine, 34, 757-764.

Sheflin, A. A., \& Brown, D. (1996). Repressed memory or dissociative amnesia: What the science says. Journal of Psychiatry and Law, 24, 143-188.

SifNEOS, P. E. (1973). The prevalence of "alexithymic" characteristics in psychosomatic patients. Psychotherapy and Psychosomatics, 22, 255-262.

Sivers, H., Schooler, J., \& Freyd, J. J. (2002). Recovered memories. In V. S. Ramachandran (Ed.), Encyclopedia of the human brain (Vol. 4, pp. 169-184). San Diego, CA: Academic Press.

Stewart, S., \& CONRod, P. J. (2003). Psychosocial models of functional associations between posttraumatic stress disorder and substance use disorder. In P. Ouimette \& P. J. Brown (Eds.), Trauma and substance abuse: Causes, consequences, and treatment of comorbid disorders. (pp. 29-55). Washington, DC: American Psychological Association.
Stoler, L., Quina, K., DePrince, A. P., \& Freyd, J. J. (2001). Recovered memories. In J. Worrell (Ed.), Encyclopedia of women and gender (Vol. 2, pp. 905-917). San Diego, CA: Academic Press.

Teicher, M. H. (2002, March). Scars that won't heal: The neurobiology of child abuse. Scientific American, 68-75.

UbA, L. (2002). A postmodern psychology of Asian Americans: Creating knowledge of a racial minority. Albany: State University of New York Press.

van der Kolk, B. A., \& McFarlane, A. C. (1996). The black hole of trauma. In B. A. van der Kolk, A. C. McFarlane, \& L. Weisaeth (Eds.), Traumatic stress: The effects of overwhelming experience on mind, body, and society (pp. 3-23). New York: Guilford Press.

VARIA, R., \& ABIDIN, R. R. (1999). The minimizing style: Perceptions of psychological abuse and quality of past and current relationships. Child Abuse \& Neglect, 23, 1041-1055.

Weinbach, R. W., \& Curtiss, C. R. (1986). Making child abuse victims aware of their victimization: A treatment issue. Child Welfare, 65, 337-346.

Weingarten, K. (2003). Common shock: Witnessing violence every day. New York: Dutton.

WiLliams, L. M. (1994). Recall of childhood trauma: A prospective study of women's memories of child sexual abuse. Journal of Consulting and Clinical Psychology, 62, 1167-1176.

Wright, D. B., Loftus, E. F., \& Hall, M. (2001). Now you see it; now you don't: Inhibiting recall and recognition of scenes. Applied Cognitive Psychology, 15, 471-482.

WURR, C. J., \& PARTRIDGE, I. M. (1996). The prevalence of a history of childhood sexual abuse in an acute adult inpatient population. Child Abuse \& Neglect, 20, 867-872.

Young, M., Read, J., Barker-Collo, S., \& Harrison, R. (2001). Evaluating and overcoming barriers to taking abuse histories. Professional Psychology: Research \& Practice, 32, 407-414.

Zlotnick, C., Mattia, J. L., \& Zimmerman, M. (2001). The relationship between posttraumatic stress disorder, childhood trauma, and alexithymia in an outpatient sample. Journal of Traumatic Stress, 14, 177-187.

Zurbriggen, E. L., \& Freyd, J. J. (2004). The link between childhood sexual abuse and risky sexual behavior: The role of dissociative tendencies, information-processing effects, and consensual sex decision mechanisms. In L. J. Koenig, L. S. Doll, A. O'Leary, \& W. Pequenat (Eds.), From child sexual abuse to adult sexual risk: Trauma, revictimization, and intervention (pp. 135-158). Washington, DC: American Psychological Association. 